\title{
Impact of Big Data on Innovation, Competitive Advantage, Productivity, and Decision Making: Literature Review
}

\author{
Nadeem U. Shahid, Nasir J. Sheikh \\ Technology Management Department, The University of Bridgeport, Bridgeport, USA \\ Email: nshahid@my.bridgeport.edu,nsheikh@bridgeport.edu
}

How to cite this paper: Shahid, N. U., \& Sheikh, N. J. (2021). Impact of Big Data on Innovation, Competitive Advantage, Productivity, and Decision Making: Literature Review. Open Journal of Business and Management, 9, 586-617.

https://doi.org/10.4236/ojbm.2021.92032

Received: October 16, 2020

Accepted: March 15, 2021

Published: March 18, 2021

Copyright $\odot 2021$ by author(s) and Scientific Research Publishing Inc. This work is licensed under the Creative Commons Attribution International License (CC BY 4.0).

http://creativecommons.org/licenses/by/4.0/

\begin{abstract}
Advances in the field of technology enabled individuals and businesses to collect large amounts of data (structured and unstructured) from various sources like never before. Data from social media, user-generated, internet, health care, manufacturing, supply chain, financial institution, and sensors have grown exponentially. This paper's objective is to review how big data drive and impact innovation, competitive advantage, productivity, and decision support. Methodology: A comprehensive literature review on big data and identifying the impact of big data analytics on innovation, competitive advantage, productivity, and decision support are studied. The reviewed literature created the foundation for studying, a model that was developed based on an extensive review of literature as well as case studies and future forecast by market leaders. Big data is the latest buzzword among businesses. A new model is suggested identifying big data and the correlation between innovation, competitive advantage, productivity, and decision support. Findings: A review of scholarly literature and existing case studies finds that there is a gap between existing frameworks and the integration of big data into various business and management functions and objectives. The findings are interesting that literature is rich with concepts and frameworks for achieving the end goal for business or management function along with framework but very little is available in the literature on the question of how to integrate big data analytics into those frameworks. This paper finds that a key question is missing i.e., what are the essential steps that businesses should perform to implement and integrate big data analytics into existing frameworks to fully exploit the big data potential. Research Limitations/Implications: The research was limited to a review of selective literature focused on in-depth understanding of big data. Additionally, it focuses on how big data leads to innovation, competitive advantage, productivity, and decision support. Although there are many other related fields of studies where big data impact
\end{abstract}


can be studied but is not part of this study effort. Future studies can lead to more in-depth studies of other related areas of studies. Practical Implications: The review of the literature suggested that "Big Data" is playing an important role in innovations, creating competitive advantage, enhancing productivity, and assisting in data-driven decisions. Businesses are taking advantage of the customer insights that are innovating products and services which are very customer-centric, keeping the competition on the run, improving productivity at all levels, and making educated decisions every day. The future will be driven by smarter big data solutions and insights. Originality/Value: The study provides evidence that big data is the catalyst for innovation, creates competitive advantage, enhances productivity, and assists in decision making. The methodology is to review scholarly literature and case studies. It supports the need for developing new models, implementation frameworks for better insights, and patterns. The big data implementation methodologies, framework, and governance have been ignored in empirical research.

\section{Keywords}

Big Data, Innovation, Competitive Advantage, Decision Making

\section{Introduction}

The term Big Data is defined as large pools of data. The four characteristics of Big Data are volume, velocity, variety, and value (Mo \& Li, 2015; Özköse, Ari, \& Gencer, 2015).

The paper aims to review how Big Data is influencing innovation, competitive advantage, improving productivity, and assisting decision-makers. Figure 1 highlights the 4 essentials of big data. International Data Corporation (IDC) forecasts worldwide revenues for big data and big data analytics (BDA). Commercial purchases of BDA-related hardware, software, and services are expected to maintain a compound annual growth rate (CAGR) of $11.9 \%$ through 2020 when revenues will be more than $\$ 210$ billion.

The world is more connected today; large volumes of data are generated every day. Data volume is growing at an exponential rate by 2020 and well beyond. According to an IDC research paper from 2005 to 2020 , the digital universe will grow by a factor of 300 , from 130 exabytes to 40,000 exabytes. Big data and data insights have the potential to impact and change every industry and business process in the next few years (Kudyba \& Davenport, 2014). The growth of the digital universe is about to double every year until 2020 (Gantz \& Reinsel, 2012). With the term Big Data, the first thing coming to mind is the size of the data and the question arises: What is big data? The 3V's volume, velocity, and variety have emerged as the key characteristics of Big Data (Chen, Chiang, \& Storey, 2012; Kwon, Lee, \& Shin, 2014). Volume refers to a large amount of data businesses generate or collected over time. It includes structured as well as unstructured 


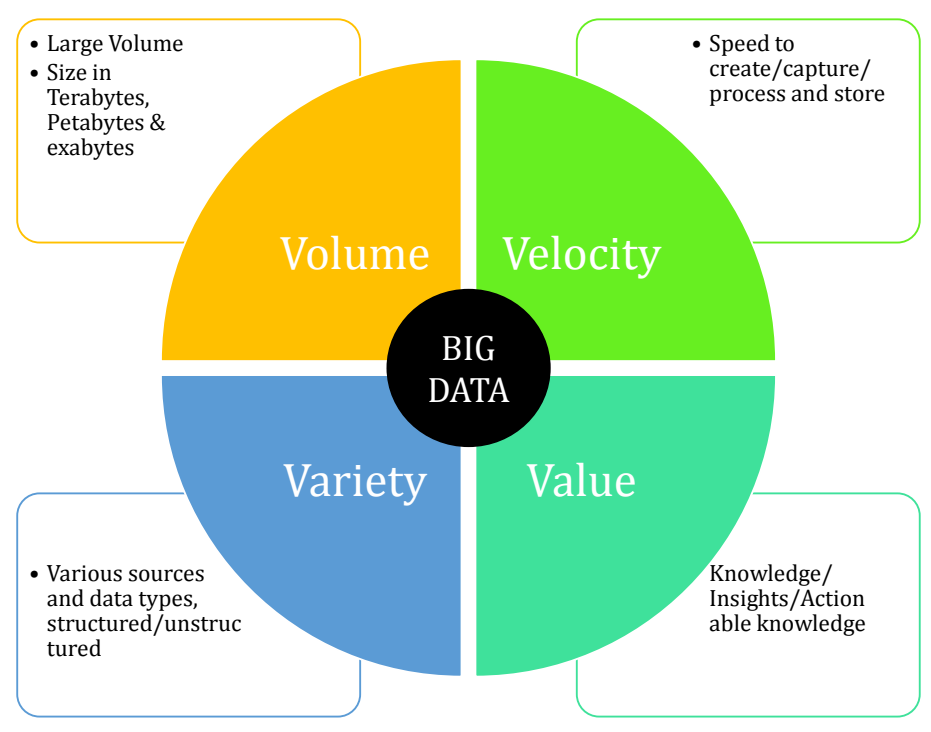

Figure 1.4 Vs of big data.

data. The growth rate of data is incredible doubling each year. Velocity refers to the speed at which data from various sources generated and processed. Businesses are more into real-time processing as compared to delayed or batched processing. Gartner (2015) forecasted that 20.8 billion devices will be connected worldwide by 2020 . Variety refers to several types of data, depending on the application system structured, semi-structured, and unstructured i.e. photo, audio, video, clickstream, and from sensors (Lee, 2017).

Large volumes of big data bring many opportunities besides a handful of challenges; businesses are achieving better insights into their data customer, products, and processes. Data insights are enabling businesses for rapid innovation which are customer-centric, improved performance, better decision making, and keeping the competition on the run (Moorthy et al., 2014; Glinska, 2016). The advancement in the technologies and data volumes has led to improvements in the functional capabilities of businesses, new avenues have been identified. New innovative and disruptive strategies are applied by businesses to break away from traditional approaches to redefine innovation, competition, and productivity (Mazzei \& Noble, 2017).

Business starting early with big data will defiantly have an added advantage. Data is a critical component of business performance, as well as its advantage of decisions supported by data, which are better quality than its competition. Such decisions are more accurate (DeLone \& McLean, 1992). High-quality volumes of data is a very valuable asset, it is not only valuable and rare, and by the same token other business cannot reproduce it as well as there is no substitute to it, it can give businesses a sustained advantage (Barney, 1991). Many businesses are rushing to take advantage of big data to set up their strategy and competing on data (Prescott, 2016).

Big data insights are impacting nearly every aspect of our lives and society, including mobile services, retail, manufacturing, financial services, life sciences, 
and physical sciences (Jagadish et al., 2014). Businesses are always quick to take advantage of the latest tools (big data analytics) to innovate, successfully outperform the competition, and minimize the threat of new entrants. Big data has a similar power to transform our lives, as historically it is proved that information technology investment and innovations have enhanced competitive performance and productivity (Hallman, Rakhimov, Plaisent, \& Bernard, 2014).

Big data insights reveal many dimensions that were never explored before, businesses are learning how their products are used by the individuals, such interesting insights are guiding the beginning of new services and design guidelines for future products (Hallman et al., 2014).

Redistributed Manufacture (RdM) takes advantage of many factors like 3D printing, assistive manufacturing, and big data offering numerous benefits over the existing system. The supply chain landscape is rapidly changing to operate effectively and efficiently (Tan, Ji, Lim, \& Tseng, 2017).

Tech America Foundation's Federal Big Data Commission in Executive Summary and Key Findings noted that Big Data has the potential to transform government and society itself. It further added Big Data as an opportunity for government agencies that seek to exploit it to enhance the business of government (TechAmerica Foundation's Federal Big Data Commission, 2012). Obama White House on May 23, 2012, started the initiative Digital Government Strategy, among the three main objectives, Big Data was emphasized by highlighting that unlocking the power of government data to spur innovation across our Nation and improve the quality of services for the American people (Office of Management and Budget, The Executive Office of the President, n.d.).

\section{Research Method}

In the research presented here, the focus is on combining the most important "previously established studies and concepts" that I have identified in the academic literature based on which I provide a synthesis that "advances our understanding" (LePine \& Adelaide, 2011).

A comprehensive literature review on Big Data and its influence on innovation, competitive advantage, productivity, and decision support has created a theoretical basis for these papers. Using a literature review, models were developed and evaluated using existing available scholarly literature. Big data is a buzzword in today's business world, businesses are looking for new ways to harness the data to innovate. The results of the review reveal that big data analytics have a mark on all four variables under discussion.

The research methods used in this study follow the principles outlined by (LePine \& Adelaide, 2011). It is a comprehensive literature review on big data. Over one hundred articles have been reviewed in relevant journals such as ELSEVIER, MIS Quarterly, ProQuest, Taylor \& Francis, and others which created a theoretical foundation of the paper.

The contribution of the study is intended to review and summarize the theoretical and empirical knowledge that should inspire new discussions and direc- 
tions for further research activity

\section{Ways to Leverage the Big Data}

Big Data can be leveraged in many ways; however, the focus of this paper is to review innovation, competitive advantage, productivity, and decision making with Big Data. Figure 2 illustrates the research themes from the Big Data perspective, which are discussed in this paper.

\section{Innovation}

IBM Institute for Business Value in collaboration with the Economist Intelligence Unit conducted (2014 IBM Innovation Survey) a latent class cluster analysis of 341 respondents' usage of big data and analytics tools for innovation. The analysis revealed organizations using big data and analytics within their innovation processes are 36 percent more likely to beat their competitors in terms of revenue growth and operating efficiency. Indeed, outperforming organizations are 23 percent more likely to use big data tools compared to others, and almost 79 percent more likely to use analytics tools (2014 IBM Innovation Survey, 2015).

Big data analytic tools are a must to analyze big data, without tools big data is just the data and by the same token without big data analytic tools, there is no analysis. Big data and big data analytical tools together have good potential for innovation (Stubbs, 2014). For the sake of clarification, Invention is a unique, original creation, however; not necessarily innovations are completely new or novel many innovations are additions or improvements to existing products, processes, or knowledge. Big data insights are improving, exiting processes, products, and knowledge.

By analyzing online reviews/customer feedback (Amazon, Best Buy, Walmart, etc.,) customer-driven design insights are enabling innovation. To start with product attributes are identified from online reviews. Based on insights various models are built to improve the existing products and services (Jin, Liu, Ji, \& Liu, 2016). Consumer opinion data is widely available from websites to social media. The usage of big data varies from business to business, well established businesses are leveraging big data to streamline processes, improve customer services, and create efficiencies. New businesses are thriving in the marketplace by offering new ways to collect, store, and analyze the data. Many startup businesses are identifying new ways to use sensors and capture the data they produce, to add value to existing products and services (Gobble, 2013). The government can use big data as a more meaningful way to understand its citizens and bring smart solutions resulting in a smart nation and happy citizens (Sharma, 2017).

The cost of storage is way down compared to the past, computing capabilities are expanding at a rapid pace, with an ease of access to services like Amazon Web Services aka AWS enabled companies to move in the direction of big data analytics. As businesses are transforming as a result of new insights, businesses are changing more innovative strategies. 


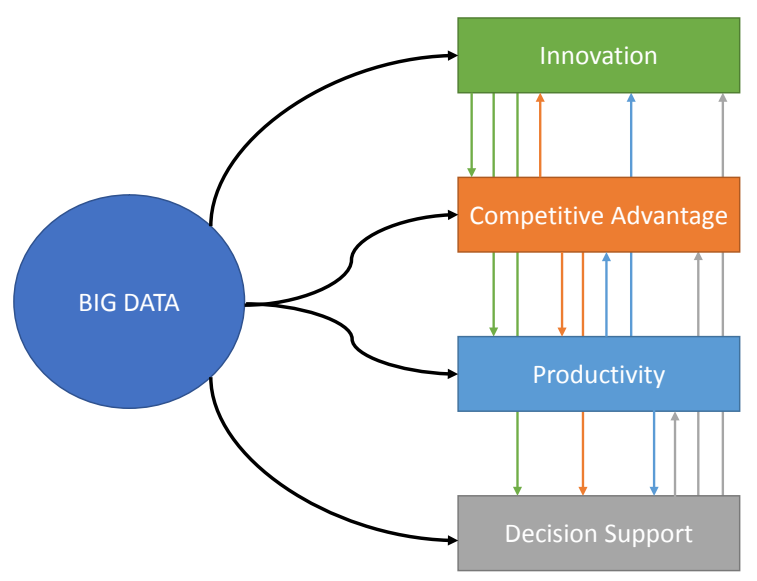

Figure 2. Big data leverage.

To address how big data is leading the innovation is beyond the scope of this paper, Figure 3 illustrates the sub-topics discussed in this paper. Henry David Thoreau (an American essayist, poet, philosopher, abolitionist, naturalist) said "It's not what you look at that matters, it's what you see."

\subsection{Innovative Products and Services}

There are many sectors in which Big Data is making difference, a few to name are aerospace, biomedicine, Internet of Things (IoT), functional interactions (human brain), clinical practices, education, vaccinology, social policy, and many more. Big data benefits are well understood in data-driven $R \& D$, developing in goods (products) and services, data-driven processes, data-driven marketing, and developing new organizations i.e. data-driven organizations. The cost of data storage is very low. Business (private/public) small or large, government departments are moving or already moved their business online. The shift of social and economic activities to the Internet resulted in tremendous volumes of data generation ... millions of gigabytes every second. To comprehend the volume, consider social networking site, according to CNN Facebook had 2.13 billion monthly active users around the world, as of December 31, 2017. The company estimates that it had an average of 1.4 billion daily active users, as of December 31, 2017. According to Pew Research national survey, 68\% of adult Internet users used Facebook as of March 1, 2018 (Bullas, 2011; C.N.N. Library, 2018).

Customer-centric products and services are very successful in the marketplace. Introducing a successful product or service feedback from stakeholders as well as consumers is a must. Unstructured data from social media, emails, research papers, tweets, news, help companies listen to their customers and stakeholders along with competitors. Insights from all the sources will help the business to incorporate customer feedback or customer preferences and needs. At the same changes can be applied quickly to existing products and services (Glinska, 2016). 


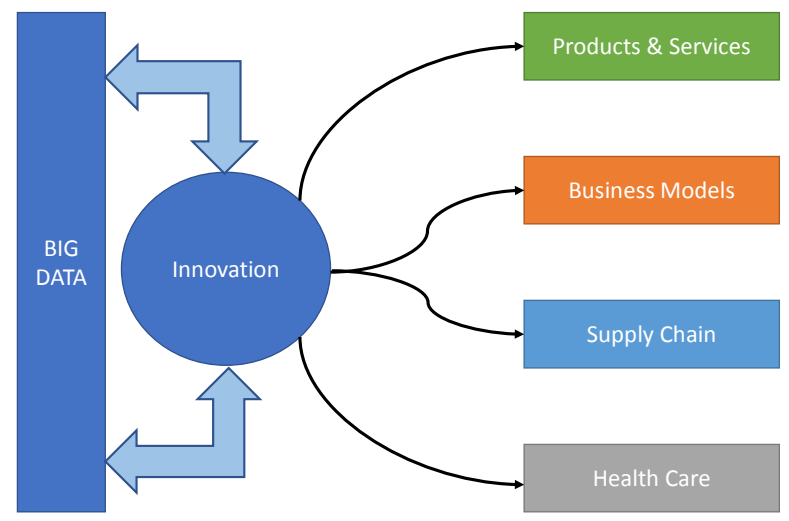

Figure 3. Data-Driven innovation.

Future innovations will be data-driven, data is a new source of growth. The Internet of Things (IoT) is a growing future technology model intended as a global network of devices or machines with the capability to interact with each other. Io $\mathrm{T}$ is one of the most desirable future technology with rapid growth (Lee \& Lee, 2015). The IoT is an environment in which applications and services are driven by data collected from devices. Devices act as sensors that interface with the real world. The predictions are the IoT is soon to be part of everybody's life.

Future innovations and growth are data-driven, the innovations in the ecosystem of IoT will touch almost every sector like health, education, agriculture, transportations, manufacturing, smart grids, and domestic home applications (OECD Science, Technology and Industry Scoreboard 2017 | READ Online, 2017).

With the growth of big data analytics, consumer analytics got maximum focus, data stored in repositories and real-time data on consumers, helped businesses to better understand their consumers, engage in various marketing activities, have better insights on the next generation of products and services.

Davenport et al. (2012) in the MIT Sloan management review said that big data is much more than that. Indeed, companies that learn to take advantage of big data will use real-time information from sensors, radio frequency identification, and other identifying devices to under their environments at a more granular level, to create new products and services.

\subsection{Business Models Transformations}

Business models are often seen as an intermediately between a company's strategy and its business processes (Morris, Schindehutte, \& Allen, 2005).

Big data insights are enabling businesses to innovate business processes and rethink business models and come up with new strategies. Figure 4 highlights how strategy is transformed into a business model and then further down into a business process model. Companies like GE and Siemens not only selling their electric grids and medical equipment but also their customers beyond regular 


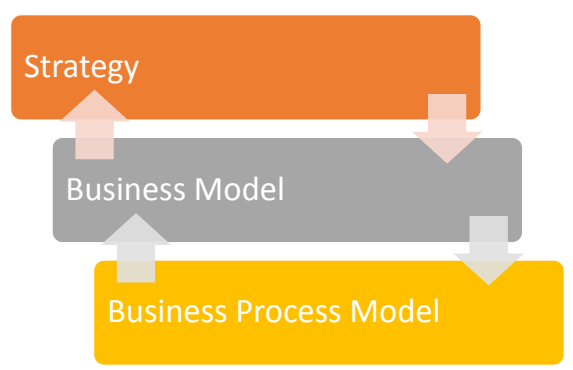

Figure 4. Business model as the intermediary between strategy and business processes (adapted from Al-Debei \& Avison, 2010).

annual maintenances on how to add value, improved efficiencies applying analytics on data collected from these devices. Uber and many others are great examples of how mobile devices, cloud technology, and data analytics have disrupted the cab industry all around the world. Big data-driven business models are creating new markets, new strategic and economic perspectives. Data is at the heart of the core logic of business model innovation (Cheah \& Wang, 2017). Information driven business models are making their impact on all the domains of various business models. Businesses can aggregate the manufacturing floor data and can combine it with the supply chain for manufacturing customers and sells software tools to improve the performance (McGuire, Manyika, \& Chui, 2012).

According to the 2014 IBM Innovation Survey 341 respondents, 79\% said they are leveraging data and analytic tools to create new business models. Big data analytics help create data transparency, in promoting innovative business models (Tan et al., 2017).

We are living in a data era; the data revolution is impacting every aspect of society and people's lives. The success of businesses is no longer just dependent on the latest technologies but on identifying a new way of doing business based on the data insights. Constantly learning and applying radical customizations, experimentation, and changing business models are the name of the game (Jiang \& Chai, 2016).

With the growth of big data insights, the firm centric view of business models is needed to transit to new data-driven models, of course, it is easy to say but have huge challenges in the transition, advancing technologies and rate of adoption of these technologies are overturning old-style business models (Bankvall, Dubois, \& Lind, 2017). Amazon's online bookstore is an excellent model of precision marketing using BDA (Guo \& Guan, 2015).

\subsection{Supply Chain Improvements}

Kumar et al. (2016) discussed that Big data has the potential to revolutionize the art of supply chain design. Big data insights are taking the supply chain to the next level. Plant operations generate huge volumes of data, big data analytics can be applied resulting better understanding of current operations compared to baseline or most optimal range for a system or piece of equipment. The proac- 
tive approach minimizes the disruptions or equipment failures, resulting in overall improved operation. Emerging supply chain solutions bundled with big data and intelligent manufacturing is the future, businesses are modernizing (Ramsey, 2014). The analysis of data collected from various sources during manufacturing and applying big data analytics deliver actionable insights.

Lamba and Singh (2017) in their research paper highlights that the properties of big data can be utilized to gain critical and fundamental insights towards optimizing the operations and supply chain. Big data has significantly important in process improvement, managing logistics, inventory management, and cost optimization. Data gathered from the production floor of factories is increasingly growing, data is flowing from all the various sources. However, the nature of such datasets is complex, traditional data processing applications are not sufficient enough to process them. Big data analytics have played a transformational role in reducing production problems, reducing waste. Predictive manufacturing and maintenance are increasingly becoming popular (Lee, Lapira, Bagheri, \& Kao, 2013).

Advances in big data analytics have led to the development of new supply chain methods and techniques for the value-added solution. For example, the bullwhip effect in the supply chain which refers to a swing in inventories in response to customer demand creates supply chain inefficiencies. Tan et al. (2017) discussed the potential of big data on the improvement of various processes, and to mitigate the effect of bullwhip as big data "velocity" bears the greatest potential to enhance performance by operationalizing the big data in control engineering analyses.

\subsection{Health Care Transformation}

The health care sector is one the largest producer of data from simple office visits to complex treatments, from simple blood-work of the lab to complex MRI data, the volume is huge. Improving quality care and offering efficiency in the health care delivery system, combining patient data with practitioner data will be critical (Murdoch \& Detsky, 2013).

Big data analytics can generate new knowledge by analyzing the huge volumes of patient data. Once new knowledge is generated, insights can be delivered directly to practitioners using big data, resulting in improved and efficient health care delivery. Figure 5, attempts to illustrate the process of gathering data, generating knowledge, and distributing knowledge for better patient outcomes.

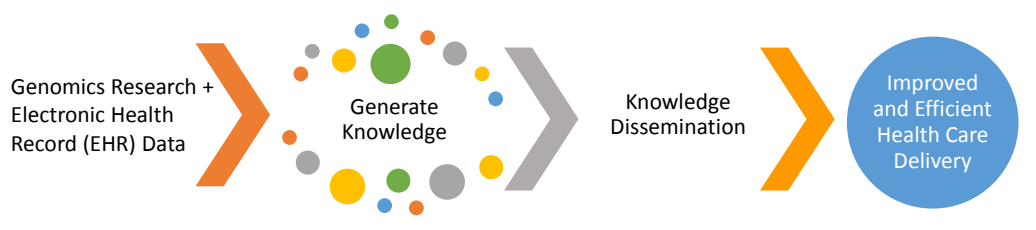

The Inevitable Application of Big Data to Health Care

Figure 5. Adapted from Murdoch \& Detsky, 2013. 
A well-working example of the above model can be studied in Israel. In Israel, every citizen is entitled to a wide-range of health-care services. Health-care services are provided by 4 non-profit national health services and insurance funds. Early 1990's these providers started working on the integration of their health records in their clinics. Data repositories served as a platform for data-driven innovation and quickly translated into practice. Data repositories enabled a unique opportunity as test grounds for new data-driven care models. Israel is an early adopter of big data analytics, telemedicine, and online patient engagement (Balicer \& Afek, 2017).

Big data analytics will have a significant role to play across the health-care field, although health-care is not at the forefront of big data analytics. Bates et al. (2014) suggested how predictive analytics can be used in health care. Some of Bates et al. (2014) suggestions are to use predictive analytics for identifying and manage six use cases which are high-cost patients, readmissions, triage, decompensations (when a patient's condition worsens), adverse events, and treatment of optimization for a disease affecting multiple organ systems. Past few years affordable health care law has enforced health-care providers to implement Electronic Health Record (HER), and data volume has increased. Big data analytics can be applied to improve quality and efficiency. Affordable care act encourages accountable care, stakes are high for clinics, insurers, purchasers, and patients to collect, analyze and exchange health-care information to eliminate waste and learn better treatments without harming patients (Larson, 2013). Khoury et al. (2014) wrote in his research paper that the combination of a strong epidemiologic foundation (relating to the branch of medicine which deals with the incidence, distribution, and control of diseases), robust knowledge integration, principles of evidence-based medicine (EBM) (is the conscientious, explicit, judicious and reasonable use of modern, best evidence in making decisions about the care of individual patients), and an expanded translation research agenda can put Big Data on the right course (Masic, Miokovic, \& Muhamedagic, 2008).

\section{Competitive Advantage}

Big data is complex, and it is not easy to draw hidden patterns and identify correlations never been straightforward. Big data analytics reveal very useful information for businesses, the goal of big data analytics is to get deep and rich insights resulting in competitive advantage (Sagiroglu \& Sinanc, 2013). Big data is already disrupting the established industries and challenging the existing business models. Big data has become a factor for competitive advantage. Businesses that can take advantage of big data will outperform data-incompetent businesses. Data equity will become very important like brand equity (Schumpeter, 2011).

Data and big data is the driver of creating value for businesses as well as a competitive advantage, as big data analytics can extract new ideas, understanding their customers, products, and markets. Big data is an important driver of 
competitive advantage for businesses (Tan, Zhan, Ji, Ye, \& Chang, 2015). There is more than one way how big data analytics are creating a positive outlook for businesses investing in big data. Lee et al., research results indicate that businesses announcement in big data analytics leads to positive stock market reactions (Lee, Kweon, Kim, \& Chai, 2017).

Data collection is extraordinary compared to a decade ago. The volume of online transactions is exploding, a simple transaction on the Amazon site can generate and store enormous data some of the data points are like searches, pages accessed, time spent on each page, clicks, and what was added to the shopping cart or removed from the shopping cart, along with IP address of shopper is stored before a final checkout is made. Businesses are increasingly investing in collecting the data but more heavily invested in analyzing the big data which is more complex but a must for keeping the competitive advantage (Prescott, 2016).

The competitive advantage is a vast topic by itself, Figure 6 highlights the sub-topics discussed under the competitive advantage theme. It is beyond the scope of this paper to discuss the majority of factors that contribute towards the competitive advantage, choices for competitive advantage differ from business to business like diversification, value chain, and culture. Traditionally as explained by Michael Porter 5 forces define the rules of competition in any industry. Porter claims, "The ultimate aim of competitive strategy is to cope with and, ideally, to change those rules in the firm's behavior" (Porter, 1985). However, in this paper Competitive advantage is reviewed through the lenses of big data and how it has revolutionized management, sustainability, customized solutions, and corporate social innovation.

\subsection{Big Data Analytics (BDA)}

$\mathrm{BDA}$ is the process of examining large volumes of data to discover hidden patterns, insights, and correlations. BDA helps businesses to identify new opportunities and creating a competitive advantage. Efficient operations, happy satisfied customers, and good profits result in a competitive advantage. BDA is creating a competitive advantage by reducing costs, introducing new products and services, and improved better decision making (Davenport \& Dyché, 2013).

Companies are investing in $\mathrm{BDA}$ and trying to make sense of the consumer data, the insights from data give businesses directions to define their strategies. McAfee and Brynjolfsson (2012) studies indicate that the use of data-driven decision making was on average $5 \%$ more productive and $6 \%$ more profitable compared to their competitor.

The use of $\mathrm{BDA}$ is leading the companies to outperform the competition. BDA will create insights, new opportunities, and new businesses to help other businesses to take advantage of big data. Figure 7, illustrates the impact of big data analytics on new creating products/services, cost reduction, and assisting in decision making. BDA will make the information transparent, more quality data, 
accurate data will be gathered, resulting in data-driven decisions and the next generation of products and services will be delivered in less time (McGuire et al., 2012).

Technology advances, social media, and advances in consumer analytics made it easier to measure the marketing efforts, marketers now have a 360-degree view of the customer. Such insights and a 360-degree view of customers is a key differentiator (Veysel Ertemel, 2015). Sprongl (2013) said taking advantage of business analytics means addressing and bringing solutions to the business problems. Business analytics must be part of the value-creating process along with other systems and organizational factors.

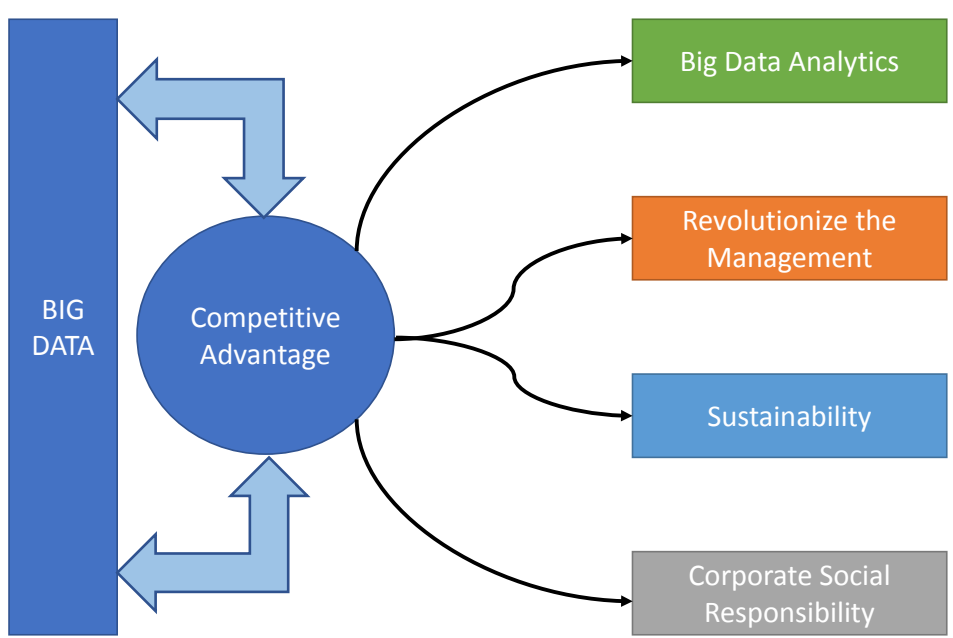

Figure 6. Data-driven competitive advantage.

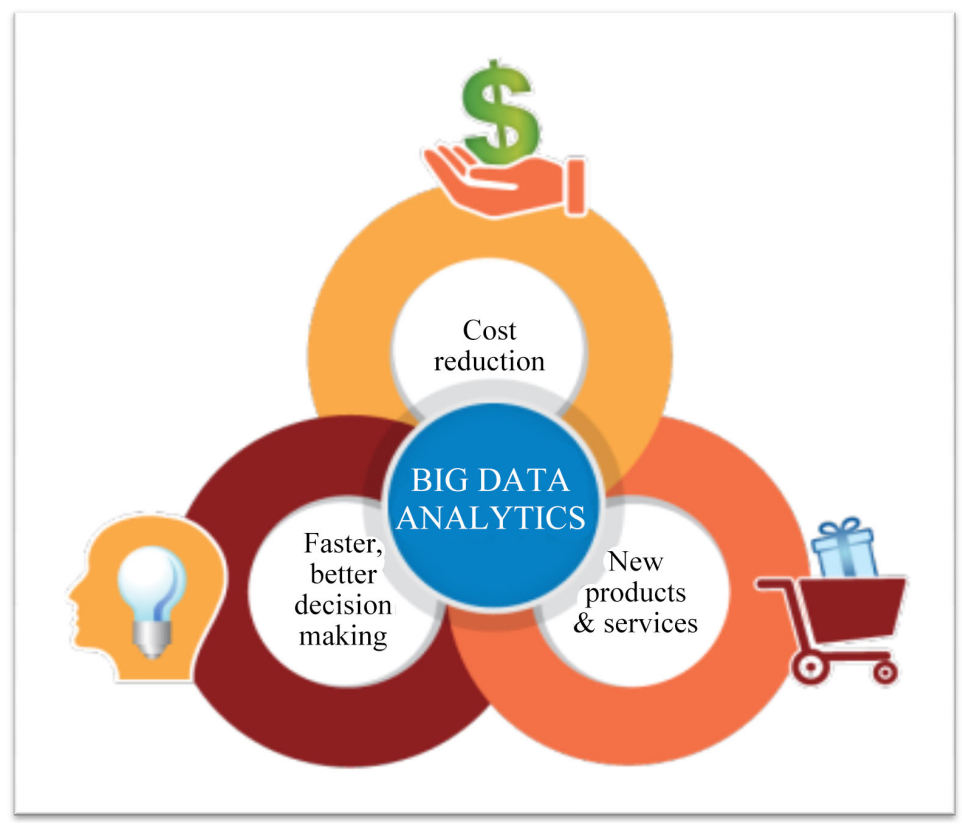

Figure 7. Big data analytics and competitive advantage adopted from (Davenport \& Dyché, 2013). 


\subsection{Revolutionize the Management}

Big Data is expanding many domains, as we saw so far. Modern predictive manufacturing i.e. analyzing data from the production floor, creating self-controlled and self-corrective processes that can reduce waste, minimize or to some extent eliminate human errors, and higher quality products at a rapid pace are revolutionizing manufacturing management. The price of sensors and data recording technologies is falling, BDA tools are improving and at the same time businesses are becoming more aware of BDA benefits, many more businesses will join the managerial revolution (McGuire et al., 2012).

Fosso Wamba et al. (2015) make a convincing argument that big data has the potential to revolutionize the art of management. Jelonek (2017) shared the results of research carried out by the EMC forum 2013. Results indicate that 79\% of entrepreneurs believe that big data provide better decision making and 58\% agreed that big data is the differentiator when it comes to industry winners and losers (Global Big Data and IT Transformation Survey, Infographic, EMC, 2013).

The human resource department has the task to hire the best talent and retain it for a longer time, however, the HR department is also affected by the tide of big data. Many view big data as a challenge when it comes to the HR department, but by the same token big data can be part of the solution. HR usually has to go through a lot of resumes, and making an assessment is a cumbersome process. Zang and Ye (2015) said in the research paper that HR continues to explore big data management, the human resource would be more accurate, efficient, and objective. Businesses are integrating their requirements into social media and professional networking websites like LinkedIn etc., information gathering is an ongoing process, in many cases, even business is not actively hiring individuals but constantly get/collect the information, which is the basis for big data analytics resulting insights into potential candidates. Such recruitment processes are more transparent.

\subsection{Sustainability}

New perspectives to find the answers, looking at the old problems under new lenses, the promise of BDA to create sustainable competitive advantage enabling businesses to exploit and leverage the power of the technology (Matthias, Fouweather, Gregory, \& Vernon, 2017). There are opportunities to create a sustainable competitive advantage.

Big data is paving the way for sustainability around innovation, supply chain, environment, and more opportunities to achieve sustainability. Big data is an enabler of behavioral change towards sustainability. Big data is bringing new heterogeneous and multidimensional perspectives on corporate environmental impacts, which are beyond simple efficiency improvements (Etzion \& Aragon-Correa, 2016). Big data may generate environmentally friendly products, for a green planet.

Insights gained from big data and new models and methods are the enabler of 
improved decision making in terms of short-term and long-term impacts that will assist and guide corporate policies, procedures, government policies for the establishment of short term and long-term sustainable management of natural and human resources. Big data integration in other parts of the society for the good of society and to solve ecological and human health issues and eventually maintain sustainability and healthy ecosystems (Song et al., 2017). Papadopoulos et al. (2017) highlighted in his case of relief operations after the Nepal earthquake in April 2015 suggest that public-private partnerships and quality information sharing can be enablers of resilience in supply chain networks for sustainability and disaster management. BDA insights require a large volume of data, sometimes data from various data sources. Belaud et al. (2014) apply a scientific simulation based on big data and collaborative work to develop sustainability in natural hazards management. Into the future and further collaboration between various partners involving big data exchange for learning and implementing sustainability open-source platform can be a way to go for sustainability activities and studies (Belaud et al., 2014).

\subsection{Corporate Social Responsibility (CSR)}

$\mathrm{Li}$ and Liu (2014) opinion is that when businesses respond to opportunities and threats in a timely fashion, competitive advantage is boosted. CSR is an ongoing effort, which requires continuous evaluation of corporate influences and at the same time, relationships with stakeholders and the environment. CSR is enabling management to identify and act in response to new opportunities and challenges (Herrera, 2015). The positive effect of CSR on financial results means excellent competitive advantage as well as good standing (Saeidi, Sofian, Saeidi, Saeidi, \& Saaeidi, 2015).

CSR is the way to achieve strategic objectives (Du, Bhattacharya, \& Sen, 2011) and at the same-time making world a better place. Today many companies are starting are have started various initiatives. The growing volume of data and better big data analytic tools can add value to CSR with better insights, the CSR can lead to competitive advantage. Customer feedback, product reviews from text messages to social media can play a greater role, defining strategy. CSR is complex, it is not only customer satisfaction but other stockholders like employees, investors, suppliers, and communities do have a greater stake in it. CSR has become in establishing a competitive advantage (Bedawy \& Shawky, 2013; Lee, Lee, Pae, \& Park, 2016).

The literature review indicates that the use of BDA is largely missing in CSR, a more focused study might be needed to find out how BDA will impact CSR.

\section{Productivity}

Productivity is measured as growth and progress. Fried et al. (1993) said in his book that productivity growth is defined as the net change in output due to a change in efficiency and technical change. Big data analytic is a new big technic- 
al change happening. Businesses aggressively using data technologies, one standard deviation higher utilization of big data technologies correlates with significant additional productivity growth, as a matter of fact, one standard deviation utilization of big data technologies associated with $1 \%-3 \%$ higher productivity (Provost \& Fawcett, 2013). Studies indicate that businesses' productivity does have a relationship with faster adoption of big data technologies, compared to their peers. Studies indicate that an average difference of $2.5 \%$ of productivity difference exists between adopters of big data and their peers (Bughin, 2016). Technology innovation has to lead to increased and enhanced productivity. Innovation in the field of big data and advanced data analytic tools have a large impact on productivity (Hallman et al., 2014).

Today's competitive business landscape forced the businesses to stay ahead of the game, do rapid decision making for improved productivity. Figure 8 highlights the sub-topics within the productivity theme discussed in this paper. Big data have a critical role to play in future manufacturing or industrial 4.0, big data is a key component of achieving self-aware and self-learning machines. Industry 4.0 is intelligent analytics and cyber-physical systems are teaming together will transform the factories and change the production management to whole new dimensions resulting in a significant boost to productivity (Lee, Kao, \& Yang, 2014).

\subsection{Energy Efficiency Enhancement}

Modern building with the help of sensors generates large volumes of operational data, capturing the details of building operations, the analysis of big data results in energy efficiency enhanced solutions. According to International Energy Agency (IEA), buildings are the largest energy consumers accounting for $1 / 3$ of final energy consumption globally and equal contributors to carbon dioxide emissions (Fan, Xiao, Li, \& Wang, 2018). Fan et al. (2018) said in the research paper big data analytics will play an essential role in the building industry. The goal of modern building construction and operations is to reduce the carbon footprint (Moreno et al., 2016) using big data analytic models to form strategies for day-to-day operations of the building. Energy consumption is on the rise it is predicted that there will increase of $37.5 \%$ in energy consumption every 10 years. Big data and IoT is an excellent combination that can be applied to smart building (Moreno et al., 2016).

For the future of our planet earth, which we call our home it is essential to construct and manage the buildings in a sustainable way, the energy-efficient building is a concern at large by public and developers, to analyze the energy consumption behavior big data analytics can be applied to help improve the energy efficiency of the buildings resulting in energy conservation (Koseleva \& Ropaite, 2017). A case study by Wang et al. (2017) in which he and fellow researchers studied the performance management of boiler by big data platform and big data analysis methods resulted in a favorable forecasting load of boilers was remarkable energy saving of $9 \%$. 


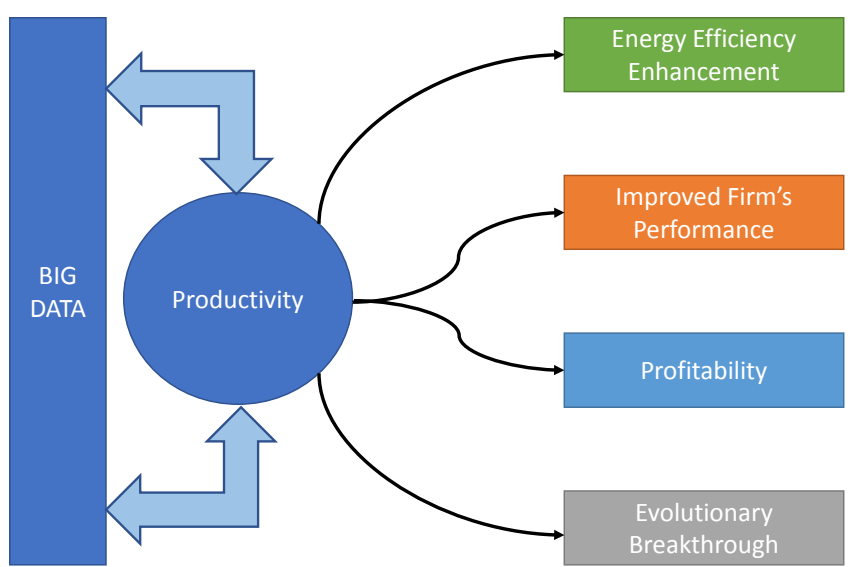

Figure 8. Data-driven productivity.

The rapid growth and improvements in sensor technologies are paving its way for very large datasets, future big data analytics will offer insights on the fly, and machine-generated data will be available in abundance (Ang, Seng, \& Zungeru, 2018). IBM estimated that the volume of machine-generated will increase $42 \%$ of all data by 2020, up from 11\% in 2005 (IBM Analytics, Industry, Australia, n.d.).

\subsection{Improved Firm Performance}

Robust IT capabilities are key dimensions in a big data environment, the level of their applications in various business functions can differentiate firm performance (Davenport \& Quirk, 2006). BDA are making its place in businesses to enhance business performance, business at an early stage of adoption and full value and strength of BDA is not fully realized (Akter, Wamba, Gunasekaran, Dubey, \& Childe, 2016).

Technological capabilities do affect the business performance, it depends on the business process quickness to respond to strategic challenges and opportunities, there is a direct relationship between quickness to respond and information technology (Chen et al., 2014) thus improved capability to respond to challenge and opportunities result in better performance and eventually better profits, growth, and market share.

BDA application is not limited to businesses but various sectors of the society and businesses are benefiting from better insights for example in the insurance sector by offering better prices, good customer management, and loss prevention can improve performance using analytic capabilities (Naik \& Joshi, 2017). No matter which industry or sector BDA is driving the leverage of data-driven initiatives, it is becoming a new norm and way for businesses to improve performance and keep the competition on the run (Worster, Weirich, \& Andera, 2014).

Time is the essence, as one of the characteristics of big data is the velocity in which data is gathered, analytics insights must be near real-time, to get the advantage and performance improvements. It has to be quick enough before data is stale (Horan, 2016). 


\subsection{Profitability}

Businesses aggressively applying analytics are performing better than their peers in the same industry, successfully transformed businesses are experienced with applying analytics across the broad range of functions, the cultural change for analytics have already in place, such businesses are investing more into niche analytics and focused on driving customer profitability (LaValle, Lesser, Shockley, Hopkins, \& Kruschwitz, 2011). Today's businesses are pursuing BDA to profit from all the various sources of data, to maximize the profits big data has to be part of the culture (Raguseo \& Vitari, 2018). BDA insights on customer's preferences, satisfaction can result in long term customer and repeat orders mean profit.

Big data analytics tools can assist the business leader to strategize future roadmap, knowledge, and insights from big data are the key player to help strategize the future (Stuke, 2015). Today decision-makers and strategists rely on big data, financial planners, chief financial officers are of the view that big data is one of the most important assets they have when it comes to enhanced profitability (Clayton, 2013).

According to the Gartner-EFI survey to understand the CFO's technology view in 2016, analytics is the top priority i.e. improvements in processes that use business analytics, and business analytics (Iervolino \& Van Decker, 2016). CFO's favorable views and business analytics as top priority lead me to believe that these investments must higher rate of return and high profits. Guo \& Guan (2015) indicated in the paper that BDA will for sure bring new profit growth for businesses.

\subsection{Evolutionary Breakthrough}

Big data is very valuable to produce evolutionary breakthroughs in scientific disciplines, enabling researchers/scientist to make evolutionary progress in many fields, future holds good for big data when it comes to competition and evolutionary breakthrough discoveries in science, engineering, medicine, commerce, education and national security (Philip Chen \& Zhang, 2014).

Scientists are looking at great unique opportunities e.g. plant phenology, the study of repeating events in the life of plans has gained interest in many sectors of society. Scientists are interested in studying the effects of climate change on the life cycle of the plants, with recently available technologies data from ecology, evolutionary biology, climate science and remote sensors are gathering has maximized, in the absence of standard phenology models at ecosystems, it appears to be that big data analytics for plant phenology has to promise for a breakthrough in process-based phenology modeling (Tang et al., 2016). Another interesting area of big data breakthrough in immunology (the study of immune systems in all organisms) is on the brink of a big data-driven breakthrough (Snijder, Kandasamy, \& Superti-Furga, 2014). 
Braskem a Brazilian petrochemical company sees big breakthroughs with BDA in helping to unlock the way to renewable chemical discoveries (Greenwood, 2017).

\section{Decision Support}

Big data analytics generate many insights that lead to better decisions. Often such insights are interesting to know various probabilities. Common decisions guided by big data analytics are product development and feature prioritization, advertising testing, brand strengths, marketing mix optimization, pricing, customer segmentation, and text mining. Big data analytics assists in better and more informed decisions (Agrawal, 2014). Decision support systems introduced as early as in the mid-1960s have improved the effectiveness and efficiency. Advanced predictive analytics enabled more data-driven researches. As mentioned earlier data collection by every business has grown beyond imagination, big data analytics begin by analyzing data, and making reliable predictions is where new organizational competencies for decision-making and competitive advantage begin (Bakos \& Brynjolfsson, 2000).

Big data insights are very valuable and with the promise of better decision making for critical development areas like health care, economic productivity, energy, and natural disaster prediction (Yi, Liu, Liu, \& Jin, 2014). Sivarajah et al. said that extant research studies have demonstrated that substantial value and competitive advantage can be attained by businesses from taking effective decisions based n data (Sivarajah et al., 2017). Businesses are aggressively seeking to make their business decisions by leveraging big data. In a nutshell, big data can create value for the business as well as boost revenues through value (Segarra et al., 2016). No matter the size of the business, majority businesses are considering exploiting the power of big data to improve their decision making. Big data future technologies have promise new methods aimed at effectively using massive amounts of data to support decision making and knowledge discovery activities (Storey \& Song, 2017).

\subsection{Data-Driven Decision Making}

Traditional decision making is slowly complemented by data-driven decisions. The human decision-making process is complex, individual intuitions and sometimes personal bias plays a role too. The adoption of BDA has introduced new models of decision-making models (Guo \& Guan, 2015). Big data insights are assisting decision-makers in many aspects of the business, Figure 9 highlight the sub-topics discussed under the decision support theme. Businesses have various data sources and quite these data sources are in a silo, combining these swim-lines is not an easy task, big data analytic tools offer the opportunity to combine these silo data sources in one place, enabling businesses to take advantage of these data-driven capabilities to make better decisions (Badrakhan, 2010). 


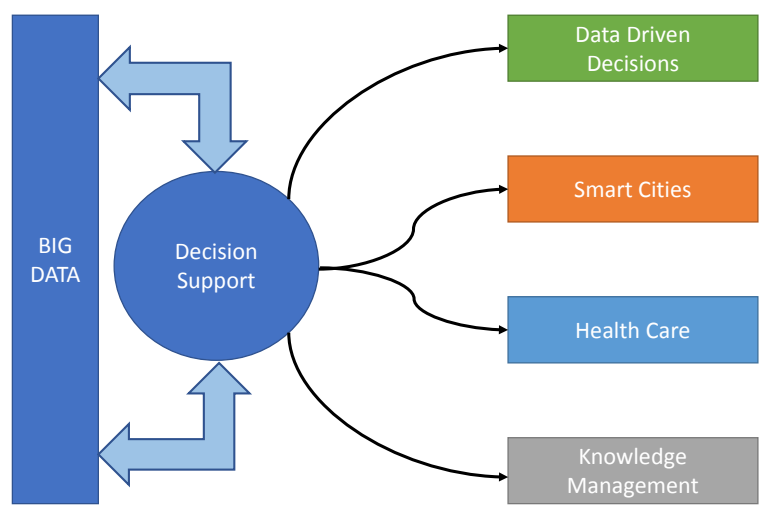

Figure 9. Data-driven decision support.

Behind successful decisions, there is more than personal instincts but accurate data, quality data which can be coupled with other factors to make decisions. Raths (2016) emphasized in the research paper that real-time data points are essential for making better data-driven decisions. Wetzel (2014) discussed his experiences while running Palmer Foundry said that within less than two years, he started seeing the benefits of unlocking the power of data in environmental conditions and maintenance, as machinery downtime was reduced tremendously by closely watching predictive indicators and fixes took less time. One promise big data has to researchers hope to deliver that is BDA provides decision support capabilities (Power, 2014) so that they could enhance their (businesses) performance, forecasting accurately, and minimize the inventory costs (Lee et al., 2017). Extracting valuable and timely insights from big data results in smarter and more profitable business decisions (Qi, Zhang, Jeon, \& Zhou, 2016; Canizo, Onieva, Conde, Charramendieta, \& Trujillo, 2017).

\subsection{Clinical Decision Support}

HealthIT Clinical Decision Support (CDS) provides clinicians, staff, patients, or other individuals with knowledge and person-specific information, intelligently filtered or presented at appropriate times, to enhance health and health care (Clinical Decision Support | HealthIT.gov, 2018). CDS is a combination of biomedical knowledge, patient data, and reasoning, all three combined and computed generate useful information for patient care.

The Healthcare sector is the single largest producer of large volumes of most diverse data on an hourly and daily basis, most of the data is stored or is printed. It brings an excellent opportunity, by identifying patterns and associations within the data has the potential to save lives, lower the costs, higher quality care, better outcomes, detecting diseases at an early stage, healthcare fraud detection, and assist in making better \& informed decisions (Raghupathi \& Raghupathi, 2014).

Wearable health-monitoring devices that continuously monitor an individual's vital signs and collect data in real-time along combined with Electronic Health Records (EHRs), the real-time BDA insights can have a significant im- 
pact on clinical practice, assisting in identifying clinically relevant events earlier (Giambrone, Hemmings, Sturm, \& Fleischut, 2015). Healthcare providers want to take full advantage of all the data and prefer to be applied at the point of care, to better serve the patients and communities at large (Conn, 2016).

Big data insights can improve the health and safety of our communities, big data offers a lot of great potentials to assist in informed decision-making in the healthcare sector (Hilbert, 2016).

\subsection{Knowledge Management Systems}

Knowledge is no limits and no borders, a class of Information researchers have introduced a class of information systems referred to as Knowledge Management Systems, intending to support the creation, transfer, and application of knowledge in organizations (Alavi \& Leidner, 2001).

Khan and Vorley (2017) identify big data as an opportunity to discover hidden knowledge and generate new knowledge which will future-looking knowledge management, will be improving business processes and competitive advantage.

Rousseaux (2017) proposes that using big data-driven predictive analytic in knowledge collection can very creative, with BDA accuracy is no more only parameter for knowledge improvement. Big data analytics are already adding and progressing knowledge in many fields of research, big data is assisting in measuring economic effects and outcomes. Many large commerce companies have employed combined resources of (economists with statisticians and computer scientists) in online marking (Einav \& Levin, 2014; Lugmayr, Stockleben, Scheib, \& Mailaparampil, 2017).

Gobble (2013) research added reviews (Harvard Business Review) and summed the discussion as discovery activities of new knowledge forces companies to challenge existing assumptions and examine new perspectives.

\subsection{Smart Cities}

The BDA has capabilities to transform our cities and homes aka Smart City / Smart Home. The growth of information technology, communication technologies, rise, and growth of big data offers the strategic, tactical, and operational makers the capabilities to work on Smart Cities (Chichernea, 2014). Every city small, medium, and big cities face traditional problems like waste recycling, wastewater removal, sanitation, water supply, clean energy. Having collected various city indicators in real-time, and analyzed for insights and implemented on model cities can lead to larger success when the smart cities model is implemented in medium and large cities (Lugaric \& Krajcar, 2016).

Baker and Mahmood (2012) in his research paper case study discusses the significance of the ability to analytically establish a set of scenarios based on information supplied from all key stakeholders which are a real challenge, analytics helped to evaluate transportation options, models, and rely on decision models.

The city government have wealth of data like geographical, traffic, energy, etc., 
which using big data analytics can be combined with data from other sources like social media, forums, and blogs can facilitate transparency, governance, trustworthiness, and engaging citizens' to participate in decision-making in smart cities (Matheus, Janssen, \& Maheshwari, 2020).

Data is an integral component of smart cities, city data is neutral of majority political influences, compared to what happened in the cities on social and economic fronts, insights provide pieces of evidence for policymaking, and proactive city planning (Kitchin, 2014).

Big data has characteristics of large volume, velocity, value, and variety. Big data can be structured, unstructured, or a combination of both. The relationship between innovation, competitive advantage, productivity, and decision support is obvious in the literature.

Innovation leads to competitive advantage, which could be in enhanced productivity and decision support as illustrated in Figure 10.

BDA discovers hidden patterns and trends increasing disrupting the businesses, businesses are identifying opportunities and exploiting those opportunities bought by BDA. In the marketplace businesses are using big data to have better consumer engagements, reaching to our new customers with their marketing campaign, and enhance the efficiency of the operations. As said big data is disruptive and influenced many industries successfully to introduce new products or services, or enhance features of existing products and services, Netflix, Amazon are the leading example of companies exploiting big data. Other examples are L'Oréal using big data to personalize shopping and educating consumers, NFL leveraged RFID technology to deepen the fan experience and city-wide fitness tracker makes Chicago the first "Smart City". BDA is disrupting supply chain management; business models are transforming to take advantage of BDA insights into consideration and not to forget healthcare sectors are aggressively looking for analyzing mountains of data generated every single day. Innovative business models are important from the strategic aspect of the businesses' rapid

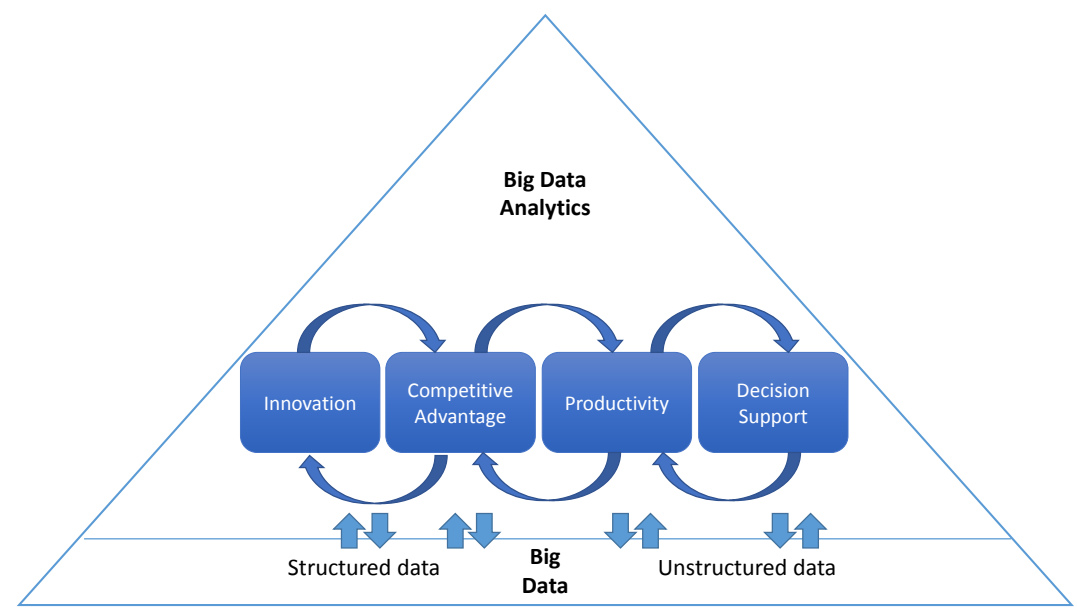

Figure 10. Big data analytics and better insights. 
response to competition and for resilience.

Businesses are making BDA part of their daily business activities, resulting in rapid change and optimizing business processes. Sensor technologies have made it simple to gather the data on anything, process the numbers, and have insights, new knowledge, and recommendation to adjust processes.

Big data is becoming a key integral component of business strategy to outperform peers, resulting in new growth opportunities. The new competitive advantage is not how companies can acquire or store the data but acquiring more quality data and use the data effectively, big data is big business.

Big data is bringing transparency and data is more accessible which was never the case, many businesses are threatened which were relying on proprietary data as a competitive asset. Many new businesses have started offering data and analytic services in almost every domain, such businesses are helping other businesses to grow faster and smarter, for example, manufacturing businesses are integrating data collected from the production floor and other sources, collecting data from suppliers from all over the world, resulting in greater collaboration during the design phase, which will eventually lead to the determination of manufacturing processes and final cost.

Real-time BDA is a must for any and every customer-facing companies, making the real-time personalized suggestion is a thing of the past the future is where a business will be able to make the consumer behavior model in real-time by analyzing clickstream, and their personal preferences. Online retailing is predominately data-driven, data collection from the social network, location, purchase history, and customer preferences lead to further deep analytics of consumer behavior.

Data-driven productivity is also on the rise, businesses are applying BDA as a significant productivity driver. Big data analytics can guide the management where there is room for improvements, such ongoing analytics identify new opportunities for improvements as more and quality data is gathered. Big data gives a broad view of internal capabilities and external opportunities. Businesses taking advantage of data, creating new models that lead the businesses to the next level on innovation, competitive advantage, performance, and better decision making are completely transformed, capable of predicting the future of the business, big data is the big game.

Big data is transforming businesses their decision-making processes. Businesses are leveraging big data to create a responsive decision-making process and streamline decision making by taking advantage of insight in a timely fashion. In-fact the agility of business is the key to surviving in the face of constant change and is the best strategy. Clinical decision support, knowledge management, and smart cities are a few examples of leveraging the decision support systems every day. BDA for decision support has few other benefits which surface when business managers discuss or consider a decision support system such as it saves time and enhances the effectiveness of the decision making. Although 
historical decision-making parameters were experience and human intuitions, which for some decision-makers still hold the truth BDA insights do challenge the intuitions which are based on experience, and BDA insights are predictive.

Large pools of the data (big data) when put together for analysis to get better insights and understanding to make a better decision is and will be the basis of competition and growth of individual businesses, adding value to the economy, sustainable environment by reducing waste, enhancing business's performance resulting in high profitability and better-quality products and services.

\section{Discussion}

Knowledge extract from big data insights has significant value that businesses are taking advantage to innovate new products and services, gain competitive advantage, enhance productivity, and better decision support.

This research paper provides theoretical evidence based on a literature review to validate the idea that a large volume of a variety of historical as well as real-time data combined with external data sources and applied big data analytics can produce insights to gain competitive advantage, and efficiencies in other areas. To summarize Figure 11 highlights all the sub-topics discussed under Productivity, Innovation, Competitive Advantage, and Decision-making theme in this paper.

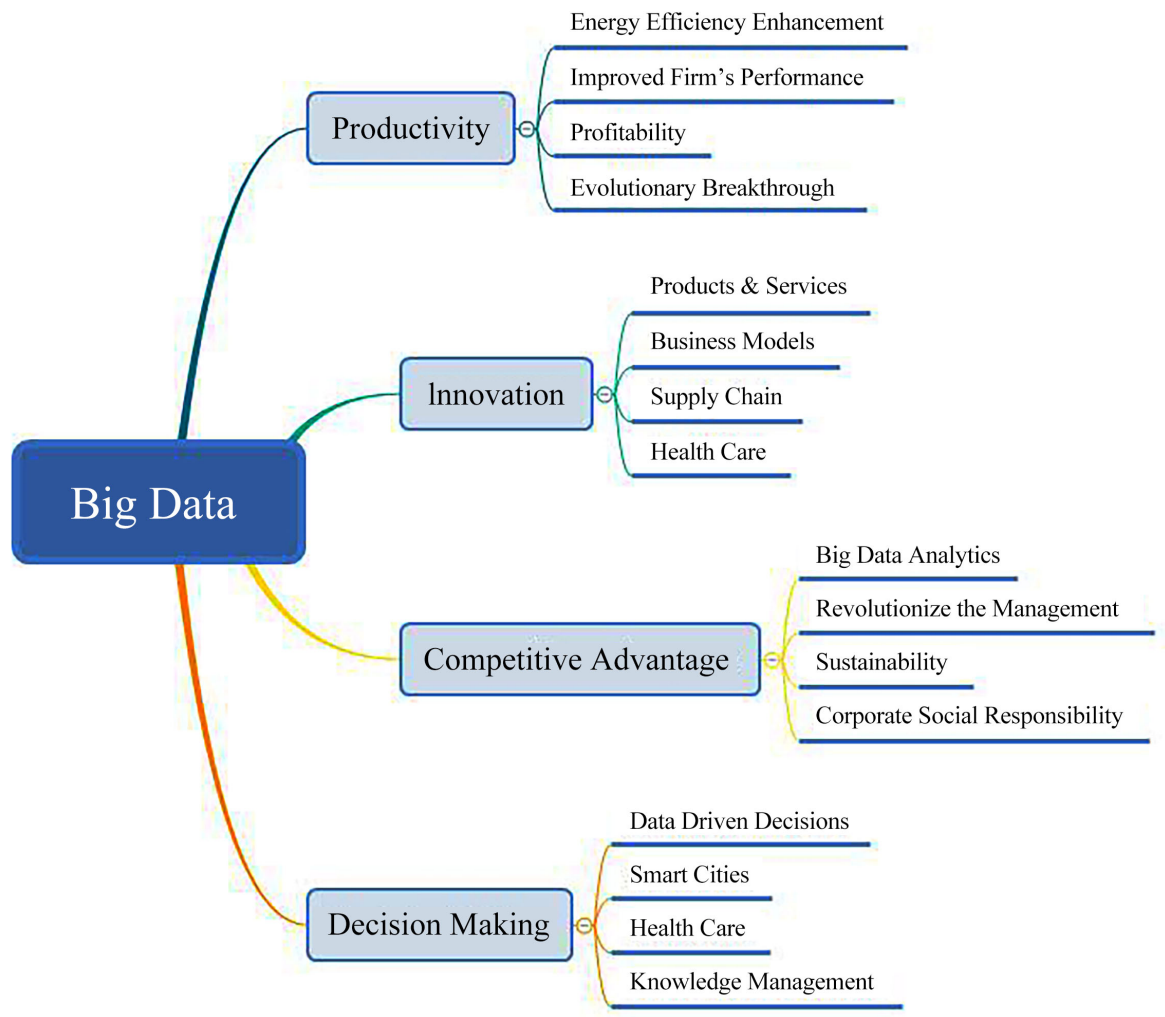

Figure 11. Big data impact of innovation, competitive advantage, productivity, and decision support. 
Big data has characteristics of large volume, high velocity, variety (structured and unstructured), and value. The volume is very large, any dataset larger than 1 terabyte falls under the category of big data. Velocity refers to the speed of data created and processing for example analysis of streaming data will give real-time insights and variety refers to different types of data like structured and unstructured (audio, video, images, free text, email, instant messages, public websites, blogs, social media channels data from industrial sensors, wearable and other monitoring devices, etc.). The combined high-volume, high-velocity, high-variety data is referred to as or termed as big data. The ability of technology to harness the internal and external data in a novel way to produce meaningful insights of significant value. Big data requires tools and methodologies which are usually different from traditional relational tools. Big data tools are a combination of various tools to capture, store and analyze to find out insights, patterns, and correlations in the data which are usually not discovered with traditional relational database tools and business intelligence reporting tools. Big data analytic insights provide forward-looking insights on the opportunity to stay ahead of the competition on innovation, productivity, and decision making.

The businesses are rapidly moving to get onboard investing a large sum of money in technologies as human resources. Early adoption of BDA has enabled the businesses to gain a significant lead over their industry peers and have successfully outperformed the competition. The market leaders are in the top quartile of financial performance when compared to their peers, and quick to respond to challenges presented to them when it comes to decision making, and defines short-term and long-term strategies. Regardless of the business, industry, sector, and size of the business, the ability to extract insights from the data enables innovation and competitive advantage gain and better insights are new sources of revenue and performance enhancement for businesses.

The use of big data provides the opportunity to explore both internal and external data historical as well as real-time to businesses potentially increasing its capabilities to innovate and compete.

Netflix's online media streaming company applied big data to improve the customer experience so the customers keep coming back to watch its programs. Netflix constantly analyzes the viewers, identifying trends and customer interests, individually consumed content, and many more details on how individuals watch content, like complete series, weekends, or leave the show half-way. BDA enabled Netflix to produce and stream the contents on a demographical and consumer preference basis which will keep the consumer engaged and keep coming back for a long-time. Data is driving Netflix's ability to deliver the content the consumer wants to see.

\section{Conclusion}

Data sets are too large, too complex, and move fast for traditional analytic technologies and tools. The big data revolution is very disruptive, many businesses 
have recognized it. It is well understood by businesses to use big data and big data analytics to raise productivity, improve decision making, and gain a competitive advantage. However, it is more complex than it appears; it does not happen in a day or by itself. Businesses are having a huge volume of transaction data which is not enough, a strategy, a detailed roadmap to get there, ready to invest in advanced analytic technologies, datasets and people is the beginning of a long journey. It requires a rethinking of processes and bringing transformational changes in an organization the way they do everyday business. Businesses need to start with the plan, to get the big data analytics work for them, identifying which data sources internally and externally can be brought together to get the value out of it. The modeling part is even more complex, pure mathematical and statistical models are built, which requires a good understanding of the modeling methods and techniques and it does not end here. Next the more critical and daunting task is how to use this information, organization transformational changes, if old methods and models are not transformed to take full advantage of new insights, then these insights are not going to add any value.

There is no magic, and data will not work on its own to bring in the insight, journey starts with a clear plan and question, business wants to find answers from big data analytic insights. If businesses are ready to brace the big data analytic, it requires a solid commitment and readiness to change the old way of doing business to data-driven models.

\section{Conflicts of Interest}

The authors declare no conflicts of interest regarding the publication of this paper.

\section{References}

2014 IBM Innovation Survey (2015). Innovative Analytics, 20.

Agrawal, D. (2014). Analytics Based Decision Making. Journal of Indian Business Research, 6, 332-340. https://doi.org/10.1108/JIBR-09-2014-0062

Akter, S., Wamba, S. F., Gunasekaran, A., Dubey, R., \& Childe, S. J. (2016). How to Improve Firm Performance Using Big Data Analytics Capability and Business Strategy Alignment? International Journal of Production Economics, 182, 113-131. https://doi.org/10.1016/j.ijpe.2016.08.018

Alavi, M., \& Leidner, D. E. (2001). Review: Knowledge Management and Knowledge Management Systems: Conceptual Foundations and Research Issues. MIS Quarterly, 25, 107-136. https://doi.org/10.2307/3250961

Al-debei, M. M., \& Avison, D. (2010). Developing a Unified Framework of the Business Model Concept. European Journal of Information Systems, 19, 359-376. https://doi.org/10.1057/ejis.2010.21

Ang, K. L. M., Seng, J. K. P., \& Zungeru, A. M. (2018). Optimizing Energy Consumption for Big Data Collection in Large-Scale Wireless Sensor Networks with Mobile Collectors. IEEE Systems Journal, 12, 616-626. https://doi.org/10.1109/JSYST.2016.2630691

Badrakhan, B. (2010). Data-Driven Decisions. Electrical Wholesaling, 91. 
Baker, D., \& Mahmood, M. N. (2012). Developing Tools to Support Complex Infrastructure Decision-Making. Smart and Sustainable Built Environment, 1, 59-72. https://doi.org/10.1108/20466091211227052

Bakos, Y., \& Brynjolfsson, E. (2000). Bundling and Competition on the Internet. Marketing Science, 19, 63-82. https://doi.org/10.1287/mksc.19.1.63.15182

Balicer, R. D., \& Afek, A. (2017). Digital Health Nation: Israel's Global Big Data Innovation Hub. The Lancet, 389, 2451-2453. https://doi.org/10.1016/S0140-6736(17)30876-0

Bankvall, L., Dubois, A., \& Lind, F. (2017). Conceptualizing Business Models in Industrial Networks. Industrial Marketing Management, 60, 196-203.

https://doi.org/10.1016/j.indmarman.2016.04.006

Barney, J. (1991). Firm Resources and Sustained Competitive Advantage. Journal of Management, 17, 99-120. https://doi.org/10.1177/014920639101700108

Bates, D. W., Saria, S., Ohno-Machado, L., Shah, A., \& Escobar, G. (2014). Big Data in Health Care: Using Analytics to Identify and Manage High-Risk and High-Cost Patients. Health Affairs, 33, 1123-1131. https://doi.org/10.1377/hlthaff.2014.0041

Bedawy, R. E., \& Shawky, Z. (2013). Upholding Competitive Advantage through Endorsing Corporate Social Responsibility: Case Study Pepsico Egypt. Procedia-Social and Behavioral Sciences, 106, 3216-3234. https://doi.org/10.1016/j.sbspro.2013.12.371

Belaud, J.-P., Negny, S., Dupros, F., Michéa, D., \& Vautrin, B. (2014). Collaborative Simulation and Scientific Big Data Analysis: Illustration for Sustainability in Natural Hazards Management and Chemical Process Engineering. Computers in Industry, 65, 521-535. https://doi.org/10.1016/j.compind.2014.01.009

Bughin, J. (2016). Big Data, Big Bang? Journal of Big Data, 3, Article No. 2. https://doi.org/10.1186/s40537-015-0014-3

Bullas, J. (2011, April 28). 50 Fascinating Facebook Facts and Figures. http://www.jeffbullas.com/50-fascinating-facebook-facts-and-figures/

C.N.N. Library, C.N.N. (2018, March 22). Facebook Fast Facts. https://www.cnn.com/2014/02/11/world/facebook-fast-facts/index.html

Canizo, M., Onieva, E., Conde, A., Charramendieta, S., \& Trujillo, S. (2017). Real-Time Predictive Maintenance for Wind Turbines Using Big Data Frameworks. 2017 IEEE International Conference on Prognostics and Health Management, Dallas, TX, 19-21 June 2017, 70-77. https://doi.org/10.1109/ICPHM.2017.7998308

Cheah, S., \& Wang, S. (2017). Big Data-Driven Business Model Innovation by Traditional Industries in the Chinese Economy. Journal of Chinese Economic and Foreign Trade Studies, 10, 229-251. https://doi.org/10.1108/JCEFTS-05-2017-0013

Chen, H., Chiang, R. H. L., \& Storey, V. C. (2012). Business Intelligence and Analytics: From Big Data to Big Impact. MIS Quarterly, 36, 1165-1188. https://doi.org/10.2307/41703503

Chen, Y., Wang, Y., Nevo, S., Jin, J., Wang, L., \& Chow, W. S. (2014). IT Capability and Organizational Performance: The Roles of Business Process Agility and Environmental Factors. European Journal of Information Systems, 23, 326-342.

https://doi.org/10.1057/ejis.2013.4

Chichernea, V. (2014). The Use of Decision Support Systems (Dss) in Smart City Planning and Management. Journal of Information Systems \& Operations Management, 8 , 238-251.

Clayton, R. (2013). CFOs Take Notice: Big Data May Be Your New Best Friend. Financial Executive, 29, 22-25. 
Clinical Decision Support | HealthIT.gov. (2018, April). https://www.healthit.gov/topic/safety/clinical-decision-support

Conn, J. (2016). Modern Healthcare. https://www.modernhealthcare.com/article/20160709/40THANNIVERSARY/30709998 6/harnessing-the-power-of-big-data

Davenport, T. H., \& Dyché, J. (2013). Big Data in Big Companies. https://www.iqpc.com/media/7863/11710.pdf

Davenport, T. H., Barth, P., \& Bean, R. (2012). How Big Data Is Different. MIT Sloan Management Review, 54, 43-46.

Davenport, T., \& Quirk, K. (2006). Competing on Analytics. Harvard Business Review, $84,98$.

DeLone, W. H., \& McLean, E. R. (1992). Information Systems Success: The Quest for the Dependent Variable. Information Systems Research, 3, 60-95. https://doi.org/10.1287/isre.3.1.60

Du, S., Bhattacharya, C. B., \& Sen, S. (2011). Corporate Social Responsibility and Competitive Advantage: Overcoming the Trust Barrier. Management Science, 57, 1528-1545. https://doi.org/10.1287/mnsc.1110.1403

Einav, L., \& Levin, J. (2014). Economics in the Age of Big Data. Science, 346, Article ID: 1243089. https://doi.org/10.1126/science. 1243089

Etzion, D., \& Aragon-Correa, J. A. (2016). Big Data, Management, and Sustainability: Strategic Opportunities Ahead. Organization \& Environment, 29, 147-155. https://doi.org/10.1177/1086026616650437

Fan, C., Xiao, F., Li, Z., \& Wang, J. (2018). Unsupervised Data Analytics in Mining Big Building Operational Data for Energy Efficiency Enhancement: A Review. Energy and Buildings, 159, 296-308. https://doi.org/10.1016/j.enbuild.2017.11.008

Fosso Wamba, S., Akter, S., Edwards, A., Chopin, G., \& Gnanzou, D. (2015). How "Big Data" Can Make Big Impact: Findings from a Systematic Review and a Longitudinal Case Study. International Journal of Production Economics, 165, 234-246. https://doi.org/10.1016/j.ijpe.2014.12.031

Fried, H. O., Schmidt, S. S., \& Lovell, C. A. K. (1993). The Measurement of Productive Efficiency: Techniques and Applications. Oxford: Oxford University Press.

Gantz, J., \& Reinsel, D. (2012). The Digital Universe in 2020: Big Data, Bigger Digital Shadows, and Biggest Growth in the Far East (pp. 1-16). IDC iView: IDC Analyze the Future.

Gartner (2015). Gartner Says 6.4 Billion Connected "Things" Will Be in Use in 2016, Up 30 Percent from 2015.

https://www.gartner.com/en/newsroom/press-releases/2015-11-10-gartner-says-6-billi on-connected-things-will-be-in-use-in-2016-up-30-percent-from-2015

Giambrone, G. P., Hemmings, H. C., Sturm, M., \& Fleischut, P. M. (2015). Information Technology Innovation: The Power and Perils of Big Data. British Journal of Anaesthesia, 115, 339-342. https://doi.org/10.1093/bja/aev154

Glinska, M. (2016). Data’s Big Promise: How Top Firms Find New Ways to Innovate (pp. 1-12). Charlottesville: Batten Briefings.

Global Big Data and IT Transformation Survey, Infographic, EMC (2013). https://hk.emc.com/infographics/forum2013-survey.htm

Gobble, M. M. (2013). Big Data: The Next Big Thing in Innovation. Research Technology Management, 56, 64-67. https://doi.org/10.5437/08956308X5601005 
Greenwood, A. (2017). Braskem Sees Big Data Breakthrough. ICIS Chemical Business, 291, 13-14.

Guo, C. F., \& Guan, Z. L. (2015). Innovation of Enterprise Profit Patterns Based on Big Data. 2015 International Conference on Logistics, Informatics and Service Sciences (LISS), Barcelona, 27-29 July 2015, 1-5.

Hallman, S., Rakhimov, J., Plaisent, M., \& Bernard, P. (2014). BIG DATA: Preconditions to Productivity. 2014 IEEE 13th International Conference on Trust, Security and Privacy in Computing and Communications, Beijing, 24-26 September 2014, 727-731. https://doi.org/10.1109/TrustCom.2014.95

Herrera, M. E. B. (2015). Creating Competitive Advantage by Institutionalizing Corporate Social Innovation. Journal of Business Research, 68, 1468-1474. https://doi.org/10.1016/j.jbusres.2015.01.036

Hilbert, M. (2016). Big Data for Development: A Review of Promises and Challenges. Development Policy Review, 34, 135-174. https://doi.org/10.1111/dpr.12142

Horan, T. J. (2016). Six Tips for Getting the Most Out of Big Data Analytics. Big Data Quarterly, 2, 8-9.

IBM Analytics, Industry, Australia (n.d.). https://www.ibm.com/analytics/au/en/industry/

Iervolino, C., \& Van Decker, J. (2016, July). Survey Analysis: Gartner-FEI Study Helps You Understand the CFO's Technology View in 2016.

https://www.gartner.com/doc/3375917/survey-analysis-gartnerfei-study-helps

Jagadish, H. V., Gehrke, J., Labrinidis, A., Papakonstantinou, Y., Patel, J. M., Ramakrishnan, R., \& Shahabi, C. (2014, July). Big Data and Its Technical Challenges. Communications of the ACM, 57.

https://cacm.acm.org/magazines/2014/7/176204-big-data-and-its-technical-challenges/ abstract https://doi.org/10.1145/2611567

Jelonek, D. (2017). Big Data Analytics in the Management of Business. 21st International Conference on Circuits, Systems, Communications and Computers (CSCC 2017), 125, Article ID: 04021. https://doi.org/10.1051/matecconf/201712504021

Jiang, W., \& Chai, H. (2016). Research on Big Data in Business Model Innovation Based on GA-BP Model. 2016 IEEE International Conference on Service Operations and Logistics, and Informatics (SOLI), Beijing, 10-12 July 2016, 174-177. https://doi.org/10.1109/SOLI.2016.7551682

Jin, J., Liu, Y., Ji, P., \& Liu, H. (2016). Understanding Big Consumer Opinion Data for Market-Driven Product Design. International Journal of Production Research, 54, 3019-3041. https://doi.org/10.1080/00207543.2016.1154208

Khan, Z., \& Vorley, T. (2017). Big Data Text Analytics: An Enabler of Knowledge Management. Journal of Knowledge Management, 21, 18-34. https://doi.org/10.1108/JKM-06-2015-0238

Khoury, M. J., \& Ioannidis, J. P. A. (2014). Big Data Meets Public Health. Science, 346, 1054-1055. https://doi.org/10.1126/science.aaa2709

Kitchin, R. (2014). The Real-Time City? Big Data and Smart Urbanism. Geo Journal, 79, 1-14. https://doi.org/10.1007/s10708-013-9516-8

Koseleva, N., \& Ropaite, G. (2017). Big Data in Building Energy Efficiency: Understanding of Big Data and Main Challenges. Procedia Engineering, 172, 544-549.

https://doi.org/10.1016/j.proeng.2017.02.064

Kudyba, S., \& Davenport, T. H. (Eds.) (2014). Big Data, Mining, and Analytics: Compo- 
nents of Strategic Decision Making. Boca Raton, FL: CRC Press.

Kumar, M., Graham, G., Hennelly, P., \& Srai, J. (2016). How Will Smart City Production Systems Transform Supply Chain Design: A Product-Level Investigation. International Journal of Production Research, 54, 7181-7192. https://doi.org/10.1080/00207543.2016.1198057

Kwon, O., Lee, N., \& Shin, B. (2014). Data Quality Management, Data Usage Experience and Acquisition Intention of Big Data Analytics. International Journal of Information Management, 34, 387-394. https://doi.org/10.1016/j.ijinfomgt.2014.02.002

Lamba, K., \& Singh, S. P. (2017). Big Data in Operations and Supply Chain Management: Current Trends and Future Perspectives. Production Planning \& Control, 28, 877-890. https://doi.org/10.1080/09537287.2017.1336787

Larson, E. B. (2013). Building Trust in the Power of "Big Data" Research to Serve the Public Good. JAMA, 309, 2443-2444. https://doi.org/10.1001/jama.2013.5914

LaValle, S., Lesser, E., Shockley, R., Hopkins, M. S., \& Kruschwitz, N. (2011). Big Data, Analytics and the Path from Insights to Value. MIT Sloan Management Review, 52, 21-32.

Lee, E.-M., Lee, H. J., Pae, J.-H., \& Park, S.-Y. (2016). The Important Role of Corporate Social Responsibility Capabilities in Improving Sustainable Competitive Advantage. Social Responsibility Journal, 12, 642-653. https://doi.org/10.1108/SRJ-11-2015-0163

Lee, H., Kweon, E., Kim, M., \& Chai, S. (2017). Does Implementation of Big Data Analytics Improve Firms' Market Value? Investors' Reaction in Stock Market. Sustainability, 9, 978. https://doi.org/10.3390/su9060978

Lee, I. (2017). Big Data: Dimensions, Evolution, Impacts, and Challenges. Business Horizons, 60, 293-303. https://doi.org/10.1016/j.bushor.2017.01.004

Lee, I., \& Lee, K. (2015). The Internet of Things (IoT): Applications, Investments, and Challenges for Enterprises. Business Horizons, 58, 431-440. https://doi.org/10.1016/j.bushor.2015.03.008

Lee, J., Kao, H.-A., \& Yang, S. (2014). Service Innovation and Smart Analytics for Industry 4.0 and Big Data Environment. Procedia CIRP, 16, 3-8.

https://doi.org/10.1016/j.procir.2014.02.001

Lee, J., Lapira, E., Bagheri, B., \& Kao, H. (2013). Recent Advances and Trends in Predictive Manufacturing Systems in Big Data Environment. Manufacturing Letters, 1, 38-41. https://doi.org/10.1016/j.mfglet.2013.09.005

LePine, J., \& Adelaide, K. (2011). Editors' Comments: Developing Novel Theoretical Insight from Reviews of Existing Theory and Research. Academy of Management Review, 35, 506-509. https://doi.org/10.5465/amr.35.4.zok506

Li, D., \& Liu, J. (2014). Dynamic Capabilities, Environmental Dynamism, and Competitive Advantage: Evidence from China. Journal of Business Research, 67, 2793-2799. https://doi.org/10.1016/j.jbusres.2012.08.007

Lugaric, L., \& Krajcar, S. (2016). Transforming Cities towards Sustainable Low-Carbon Energy Systems Using Emergy Synthesis for Support in Decision Making. Energy Policy, 98, 471-482. https://doi.org/10.1016/j.enpol.2016.09.028

Lugmayr, A., Stockleben, B., Scheib, C., \& Mailaparampil, M. A. (2017). Cognitive Big Data: Survey and Review on Big Data Research and Its Implications. What Is Really "New" in Big Data? Journal of Knowledge Management, 21, 197-212. https://doi.org/10.1108/JKM-07-2016-0307

Masic, I., Miokovic, M., \& Muhamedagic, B. (2008). Evidence Based Medicine-New Approaches and Challenges. Acta Informatica Medica, 16, 219-225. 
https://doi.org/10.5455/aim.2008.16.219-225

Matheus, R., Janssen, M., \& Maheshwari, D. (2020). Data Science Empowering the Public: Data-Driven Dashboards for Transparent and Accountable Decision-Making in Smart Cities. Government Information Quarterly, 37, Article ID: 101284. https://doi.org/10.1016/j.giq.2018.01.006

Matthias, O., Fouweather, I., Gregory, I., \& Vernon, A. (2017). Making Sense of Big Data-Can It Transform Operations Management? International Journal of Operations \& Production Management, 37, 37-55. https://doi.org/10.1108/IJOPM-02-2015-0084

Mazzei, M. J., \& Noble, D. (2017). Big Data Dreams: A Framework for Corporate Strategy. Business Horizons, 60, 405-414. https://doi.org/10.1016/j.bushor.2017.01.010

McAfee, A., \& Brynjolfsson, E. (2012, October 1). Big Data: The Management Revolution. https://hbr.org/2012/10/big-data-the-management-revolution

McGuire, T., Manyika, J., \& Chui, M. (2012). Why Big Data Is the New Competitive Advantage. Ivey Business Journal (Online).

Mo, Z., \& Li, Y. (2015). Research of Big Data Based on the Views of Technology and Application. American Journal of Industrial and Business Management, 5, 192-197. https://doi.org/10.4236/ajibm.2015.54021

Moorthy, D. M., Baby, R., \& Senthamaraiselvi, S. (2014). An Analysis for Big Data and its Technologies. International Journal of Computer Science Engineering and Technology, 4, 412-418.

Moreno, M. V., Dufour, L., Skarmeta, A. F., Jara, A. J., Genoud, D., Ladevie, B., \& Bezian, J.-J. (2016). Big Data: The Key to Energy Efficiency in Smart Buildings. Soft Computing, 20, 1749-1762. https://doi.org/10.1007/s00500-015-1679-4

Morris, M., Schindehutte, M., \& Allen, J. (2005). The Entrepreneur's Business Model: Toward a Unified Perspective. Journal of Business Research, 58, 726-735.

Murdoch, T. B., \& Detsky, A. S. (2013). The Inevitable Application of Big Data to Health Care. JAMA, 309, 1351-1352. https://doi.org/10.1001/jama.2013.393

Naik, K., \& Joshi, A. (2017). Role of Big Data in Various Sectors. 2017 International Conference on I-SMAC (IoT in Social, Mobile, Analytics and Cloud) (I-SMAC), Palladam, 10-11 February 2017, 117-122. https://doi.org/10.1109/I-SMAC.2017.8058321

OECD Science, Technology and Industry Scoreboard 2017 | READ Online (2017). https://read.oecd-ilibrary.org/science-and-technology/oecd-science-technology-and-in dustry-scoreboard-2017 9789264268821-en

Office of Management and Budget, The Executive Office of the President (n.d.). Digital Government: Building a 21st Century Platform to Better Serve the American People. https://obamawhitehouse.archives.gov/sites/default/files/omb/egov/digital-government /digital-government.html

Özköse, H., Ari, E. S., \& Gencer, C. (2015). Yesterday, Today and Tomorrow of Big Data. Procedia-Social and Behavioral Sciences, 195, 1042-1050. https://doi.org/10.1016/j.sbspro.2015.06.147

Papadopoulos, T., Gunasekaran, A., Dubey, R., Altay, N., Childe, S. J., \& Fosso-Wamba, S. (2017). The Role of Big Data in Explaining Disaster Resilience in Supply Chains for Sustainability. Journal of Cleaner Production, 142, 1108-1118.

https://doi.org/10.1016/j.jclepro.2016.03.059

Philip Chen, C. L., \& Zhang, C.-Y. (2014). Data-Intensive Applications, Challenges, Techniques and Technologies: A Survey on Big Data. Information Sciences, 275, 314-347. https://doi.org/10.1016/j.ins.2014.01.015 
Porter, M. E. (1985). The Competitive Advantage: Creating and Sustaining Superior Performance. New York: Free Press.

https://www.hbs.edu/faculty/Pages/item.aspx?num=193

Power, D. J. (2014). Using "Big Data” for Analytics and Decision Support. Journal of Decision Systems, 23, 222-228. https://doi.org/10.1080/12460125.2014.888848

Prescott, M. E. (2016). Big Data: Innovation and Competitive Advantage in an Information Media Analytics Company. Journal of Innovation Management, 4, 92-113. https://doi.org/10.24840/2183-0606 004.001 0007

Provost, F., \& Fawcett, T. (2013). Data Science and Its Relationship to Big Data and Data-Driven Decision Making. Big Data, 1, 51-59. https://doi.org/10.1089/big.2013.1508

Qi, J., Zhang, Z., Jeon, S., \& Zhou, Y. (2016). Mining Customer Requirements from Online Reviews: A Product Improvement Perspective. Information \& Management, 53, 951-963. https://doi.org/10.1016/j.im.2016.06.002

Raghupathi, W., \& Raghupathi, V. (2014). Big Data Analytics in Healthcare: Promise and Potential. Health Information Science and Systems, 2, Article No. 3.

https://doi.org/10.1186/2047-2501-2-3

Raguseo, E., \& Vitari, C. (2018). Investments in Big Data Analytics and Firm Performance: An Empirical Investigation of Direct and Mediating Effects. International Journal of Production Research, 56, 5206-5221. https://doi.org/10.1080/00207543.2018.1427900

Ramsey, M. (2014). Using “Big Data” to Deliver a Competitive Advantage. Barrington, IL: Plant Engineering. https://search-proquest-com.libproxy.bridgeport.edu/docview/1512407351/abstract/1D 609390AFF24A1APQ/1

Raths, D. (2016). Data-Driven Decisions. Long-Term Living, 65, 16-19.

Rousseaux, F. (2017). BIG DATA and Data-Driven Intelligent Predictive Algorithms to Support Creativity in Industrial Engineering. Computers \& Industrial Engineering, 112, 459-465. https://doi.org/10.1016/j.cie.2016.11.005

Saeidi, S. P., Sofian, S., Saeidi, P., Saeidi, S. P., \& Saaeidi, S. A. (2015). How Does Corporate Social Responsibility Contribute to Firm Financial Performance? The Mediating Role of Competitive Advantage, Reputation, and Customer Satisfaction. Journal of Business Research, 68, 341-350. https://doi.org/10.1016/j.jbusres.2014.06.024

Sagiroglu, S., \& Sinanc, D. (2013). Big Data: A Review. 2013 International Conference on Collaboration Technologies and Systems (CTS) San Diego, CA, 20-24 May 2013, 42-47. https://doi.org/10.1109/CTS.2013.6567202

Schumpeter (2011). Business: Building with Big Data. The Economist, London, 399, 74.

Segarra, L. L., Almalki, H., Elabd, J., Gonzalez, J., Marczewski, M., Alrasheed, M., \& Rabelo, L. (2016). A Framework for Boosting Revenue Incorporating Big Data. Journal of Innovation Management, 4, 39-68. https://doi.org/10.24840/2183-0606 004.0010005

Sharma, S. (2017). Know Your Citizens: Why Big Data Maturity Will Lead to Smart Nation Innovation. Newton: EGov Innovation.

https://search-proquest-com.libproxy.bridgeport.edu/docview/1933397735/abstract/66 25A199C26E4A73PQ/1

Sivarajah, U., Kamal, M. M., Irani, Z., \& Weerakkody, V. (2017). Critical Analysis of Big Data Challenges and Analytical Methods. Journal of Business Research, 70, 263-286. https://doi.org/10.1016/j.jbusres.2016.08.001

Snijder, B., Kandasamy, R. K., \& Superti-Furga, G. (2014). Toward Effective Sharing of 
High-Dimensional Immunology Data. Nature Biotechnology, 32, 755-759. https://doi.org/10.1038/nbt.2974

Song, M., Cen, L., Zheng, Z., Fisher, R., Liang, X., Wang, Y., \& Huisingh, D. (2017). How Would Big Data Support Societal Development and Environmental Sustainability? Insights and Practices. Journal of Cleaner Production, 142, 489-500.

https://doi.org/10.1016/j.jclepro.2016.10.091

Sprongl, P. (2013). Gaining Competitive Advantage through Business Analytics. Acta Universitatis Agriculturae et Silviculturae Mendelianae Brunensis, 61, 2779-2785. https://doi.org/10.11118/actaun201361072779

Storey, V. C., \& Song, I.-Y. (2017). Big Data Technologies and Management: What Conceptual Modeling Can Do. Data \& Knowledge Engineering, 108, 50-67.

https://doi.org/10.1016/j.datak.2017.01.001

Stubbs, E. (2014). Big Data, Big Innovation: Enabling Competitive Differentiation through Business Analytics. Hoboken, NJ: John Wiley \& Sons.

http://ebookcentral.proquest.com/lib/bridgeport-ebooks/detail.action?docID=1729078 https://doi.org/10.1002/9781118914984

Stuke, K. (2015). Vision, Big Data, and the Allegory of the Cave. Open Journal of Business and Management, 3, 422-424. https://doi.org/10.4236/ojbm.2015.34041

Tan, K. H., Ji, G., Lim, C. P., \& Tseng, M.-L. (2017). Using Big Data to Make Better Decisions in the Digital Economy. International Journal of Production Research, 55, 4998-5000. https://doi.org/10.1080/00207543.2017.1331051

Tan, K. H., Zhan, Y., Ji, G., Ye, F., \& Chang, C. (2015). Harvesting Big Data to Enhance Supply Chain Innovation Capabilities: An Analytic Infrastructure Based on Deduction Graph. International Journal of Production Economics, 165, 223-233. https://doi.org/10.1016/j.ijpe.2014.12.034

Tang, J. W., Körner, C., Muraoka, H., Piao, S. L., Shen, M. G., Thackeray, S. J., \& Yang, X. (2016). Emerging Opportunities and Challenges in Phenology: A Review. Ecosphere, 7, e01436. https://doi.org/10.1002/ecs2.1436

TechAmerica Foundation's Federal Big Data Commission (2012). Demystifying Big Data. TechAmerica Foundation's.

https://bigdatawg.nist.gov/ uploadfiles/M0068 v1 3903747095.pdf

Veysel Ertemel, A. (2015). Consumer Insight as Competitive Advantage Using Big Data and Analytics. International Journal of Commerce and Finance, 1, 45-51.

Wang, W., Li, C., \& Wang, S. (2017). Big Data Used in Energy Efficiency and Load Forecasting of Heating Boilers. 2017 36th Chinese Control Conference (CCC), Dalian, 26-28 July 2017, 5638-5641. https://doi.org/10.23919/ChiCC.2017.8028253

Wetzel, S. (2014). Data-Driven Decisions. Modern Casting; Des Plaines, 104, 24, 25, 27, $29,31$.

Worster, A., Weirich, T. R., \& Andera, F. (2014). Big Data: Gaining a Competitive Edge. Journal of Corporate Accounting \& Finance, 25, 35-39. https://doi.org/10.1002/jcaf.21970

Yi, X., Liu, F., Liu, J., \& Jin, H. (2014). Building a Network Highway for Big Data: Architecture and Challenges. IEEE Network, 28, 5-13. https://doi.org/10.1109/MNET.2014.6863125

Zang, S., \& Ye, M. (2015). Human Resource Management in the Era of Big Data. Journal of Human Resource and Sustainability Studies, 3, 41-45.

https://doi.org/10.4236/jhrss.2015.31006 